\title{
CUIDADO FAMILIAR APÓS INFARTO AGUDO DO MIOCÁRDIO
}

\author{
FAMILY CARE AFTER ACUTE MYOCARDIAL INFARCTION
}

\section{CUIDADO FAMILIAR DESPUÉS DEL INFARTO AGUDO AL MIOCARDIO}

\author{
Raquel Pötter Garcia* \\ Maria de Lourdes Denardin Budó ${ }^{* *}$ \\ EDA SCHWARTZ ${ }^{* * *}$ \\ Nara Marilene Oliveira Girardon-Perlini ${ }^{* * *}$ \\ Mariane da Silva Barbosa ${ }^{* * * *}$ \\ Marciele Moreira Da SiLVA ${ }^{* * * * *}$
}

\begin{abstract}
RESUMO
Objetivo: Descrever o cuidado desenvolvido pelas famílias de pacientes após Infarto Agudo do Miocárdio. Método: Estudo qualitativo e exploratório realizado com seis famílias entre os meses de fevereiro e maio de 2012. Para a coleta de dados utilizou-se entrevista com a família. A análise temática constituiu-se de três etapas: pré-análise, exploração do material, tratamento dos resultados obtidos e interpretação. Resultados: O cuidado familiar foi organizado em duas categorias: Cuidado familiar como proteção e Cuidado familiar controlador. Percebeu-se que o modo de cuidar ocorre, muitas vezes, simultaneamente, sendo que o cuidado que protege é o mesmo que controla. Além disso, pode-se afirmar que, no interior do cuidado familiar, existem diversas formas de desenvolver o cuidado, sendo este, portanto, multifacetado. Conclusão: O cuidado familiar desenvolvido após IAM, nas famílias entrevistadas, apresenta, principalmente, características protetivas e de controle. Acredita-se que por meio desses resultados se estará delineando caminhos para a Enfermagem e as outras profissões da área da saúde, favorecendo uma visualização mais aprofundada do cuidado familiar e suas variações.
\end{abstract}

Palavras chave: Enfermagem, infarto do miocárdio, saúde da família, família, doença crônica.

\footnotetext{
ABSTRACT

Objective: To describe the care provided by families of patients after acute Myocardial Infarction. Method: Qualitative and exploratory study performed with six families between February and May of 2012. Interviews with the families were performed for data collection. The thematic analysis involved three steps: pre-analysis,

* Enfermeira. Doutoranda em Ciências do Programa de Pós-Graduação em Enfermagem (PPGEnf) da Universidade Federal de Pelotas (UFPel). Bolsista da Coordenação de Aperfeiçoamento de Pessoal de Nível Superior (CAPES). E-mail: raquelpottergarcia@gmail.com

${ }^{* *}$ Enfermeira. Doutora em Enfermagem. Docente do Departamento de Enfermagem e PPGEnf/Universidade Federal de Santa Maria (UFSM). Santa Maria, RS, Brasil. E-mail: lourdesdenardin@gmail.com

${ }^{* * *}$ Enfermeira. Doutora em Enfermagem. Docente da Faculdade de Enfermagem e PPGEnf da UFPel. Pelotas, RS, Brasil. E-mail: eschwartz@terra.com.br

${ }_{* * * *}$ Enfermeira. Doutora em Enfermagem. Docente do Departamento de Enfermagem e PPGEnf/UFSM. Santa Maria, RS, Brasil. E-mail: nara.girardon@gmail.com

${ }_{* * * * *}$ Enfermeira. UFSM. Santa Maria, RS, Brasil. E-mail: marianebarbosa.enf@gmail.com

${ }^{* * * * *}$ Enfermeira. Docente da Universidade Regional Integrada do Alto Uruguai e das Missões Uri Campus de Santiago, RS, Brasil. E-mail: enfmarciele@yahoo.com.br
} 
material exploration, processing and interpretation of results. Results: Family care was organized in two categories: Family care as protection and family care as control. It could be observed that both types of care occur, often times, simultaneously, thus providing protection and control. Furthermore, it can be stated that, within the family care, there are several ways to perform the care, making it multifaceted. Conclusion: Family care after acute myocardial infarction can be described as controlling but mostly protecting. From these results, new ways are outlined for Nursing and other health professions, providing a deeper understanding of family care and its variations

Key words: Nursing, myocardial infarction, family health, family, chronic disease.

\section{RESUMEN}

Objetivo: Describir el cuidado desarrollado por las familias de pacientes después del infarto agudo al miocardio. Método: Estudio cualitativo y exploratorio realizado con seis familias entre los meses de febrero y mayo de 2012. Para la recolección de datos se utilizó la entrevista con la familia. El análisis temático constó de tres etapas: pre-análisis, exploración del material, tratamiento de los resultados obtenidos e interpretación. Resultados: El Cuidado familiar fue organizado en dos categorias: Cuidado familiar como protección y Cuidado familiar controlador. Se percibió que el modo de cuidar ocurre, muchas veces, simultáneamente, siendo el cuidado que protege el mismo que controla. Además, se puede afirmar que, en el interior del cuidado familiar, hay distintas maneras de desarrollar el cuidado, siendo este, por lo tanto, multifacético. Conclusión: El cuidado desarrollado por las familias entrevistadas, después de un infarto agudo al miocardio, tiene características de control y sobre todo de protección. Por medio de estos resultados se están delineando caminos para la Enfermería, favoreciendo una visualización más profunda del cuidado familiar y sus variaciones.

Palabras clave: Enfermería, infarto del miocardio, salud de la familia, familia, enfermedad crónica.

Fecha recepción: 20/10/14 Fecha aceptación: 12/08/16

\section{INTRODUÇÃO}

As doenças cardiovasculares, são a principal causa de mortalidade de homens e mulheres acima de 30 anos nos países em desenvolvimento, como o Brasil (1). O Infarto Agudo do Miocárdio (IAM) ocasiona um elevado número de hospitalizações, sendo necessária a busca pelo serviço adequado e as orientações para identificação dos sintomas objetivando a diminuição das taxas de mortalidade (2).

Nesse contexto, as práticas de cuidado, presentes em todas as culturas, têm relevante valor, já que podem colaborar para o reestabelecimento da saúde. As experiências de cuidado são influenciadas pelos valores culturais, pela visão de mundo, fatores da estrutura social, ambiental e sistemas de cuidado à saúde (3). Assim, o cuidado é produzido em pelo menos dois contextos distintos e inter-relacionados: o sistema de cuidado profissional, representado pelos serviços de saúde, e o popular, representado especialmente pela família (3).

O conceito de "cuidado familial" (4) foi utilizado como referencial para guiar as análises desse estudo, sendo que se estabelece no grupo familiar, por meio das interações entre os seus integrantes. Objetiva proporcionar qualidade de vida e bem-estar e é determinado por um guia interno utilizado pela família, ou seja, uma orientação que permite que todos hajam de forma semelhante. No entanto, esse cuidado, tem mais significação quando ocorre em situações como as doen- 
ças (4), as quais exigem maior dedicação e interação da família para efetivar a recuperação do enfermo. Destaca-se que os modos de cuidar elaborados pela família se estabelecem devido ao que seus membros acreditam ser apropriado para as decisões e ações relacionadas a um cuidado cultural (3).

Diante disso, o cuidado como proteção visa a realização de práticas que têm o intuito de assegurar o bem-estar da família e, além, de manter a vida por meio do resguardo familiar, acompanha os membros da família em suas trajetórias de vida (4). O cuidado ainda, em determinadas situações, pode gerar conflitos devido às imposições que a família exerce sobre a pessoa doente (5).

Assim, o processo de cuidado, no ambiente familiar, pode ocorrer de diversas maneiras, dependendo do momento em que se concretiza (6). Estudos, majoritariamente quantitativos, sobre o cuidado relacionado ao IAM fazem referência ao perfil dos pacientes e fatores de risco (7), qualidade de vida (8) e questões que permeiam a doença em homens e mulheres. Algumas pesquisas abordam ainda as percepções (9) das pessoas que tiveram o IAM sobre a doença e a influência da família na prevenção dos fatores de risco (7) e o itinerário terapêutico percorrido no período pré-hospitalar (10). Destaca-se que nas pesquisas encontradas a família é abordada de forma generalizada e não de seu cuidado específico e suas peculiaridades, como se pretende abordar neste artigo.

Desse modo, justifica-se a necessidade de realizar estudos científicos relacionados a essa temática, a fim de aprofundar conhecimentos que subsidiem o cotidiano do trabalho com famílias, uma vez que cada vez mais se busca a inserção desse grupo nos serviços de saúde e nas políticas públicas. No momento em que a Enfermagem atentar para as perspectivas de cuidado estabelecidas na família diante de situação de IAM, poderá submergir em suas concepções e construir propostas específicas que auxiliem na condição crônica. Ainda, o compartilhamento de cuidados entre o saber informal familiar e formal pode facilitar na dialogicidade dos encontros, bem como na melhor estruturação dos cuidados. Dessa forma, a questão norteadora do estudo foi: Como é desenvolvido o cuidado pelas famílias de pessoas após IAM e para responde-la, definiu-se como objetivo do estudo descrever o cuidado desenvolvido pelas famílias de pacientes após IAM.

\section{MATERIAIS E MÉTODOS}

Este estudo de campo qualitativo descritivo e exploratório, realizado com seis famílias de pacientes pós IAM, sendo que os familiares foram sugeridos pela pessoa que teve o IAM (11). Para encontrar os participantes, foram lidos, inicialmente, os prontuários dos pacientes pós IAM de um Ambulatório de Cardiologia (AC) localizado em um hospital do sul do Brasil e selecionados os que atendiam aos critérios de inclusão, caracterizando uma amostra intencional.

Foram incluídas na pesquisa famílias que tinham uma pessoa com diagnóstico de IAM pregresso por aterosclerose em tempo de no mínimo 6 meses e máximo de 24 meses. Os integrantes das famílias que participaram do estudo foram indicados pelo doente, no momento da conversa informal no AC, ou então foram convidados por ele na primeira visita realizada pelo pesquisador no domićlio. A conformação de família utilizada neste estudo sugere a presença de pelo menos duas pessoas (12), sendo que o paciente foi uma delas. Foram excluídos os familiares que apresentassem dificuldade para comunicação verbal.

Os dados foram coletados entre os meses de fevereiro e maio de 2012, realizando-se entrevista com a família. Utilizou-se um gravador digital, com o consentimento prévio dos participantes, para armazenar as entrevistas, as quais, foram transcritas para um arquivo de computador para se efetuar a análise dos dados.

Quando os dados encontrados atende- 
ram aos objetivos da pesquisa, a coleta foi finalizada. O software Atlas Ti 6.2 (Qualitative Data Analysis) auxiliou na organização dos dados e, após, realizou-se a análise temática (11), a qual se constitui de três etapas: pré-análise, exploração do material, tratamento dos resultados obtidos e interpretação. As entrevistas foram lidas de maneira exaustiva, buscando-se os elementos repetidos referentes ao cuidado familiar. Desse modo, inicialmente, classificaram-se diferentes formas de cuidar, emergidas dos dados (análise convencional), porém ao final por aproximação de ideias e como forma de fornecer sustentação as categorias elencaram-se as mais significativas e que estão apresentadas neste artigo: cuidado de proteção e cuidado controlador.

Os participantes que aceitaram participar da pesquisa foram orientados e assinaram o Termo de Consentimento Livre e Esclarecido. $\mathrm{O}$ anonimato foi preservado por meio da adoção de nomes fictícios determinados pelo pesquisador. Assim, inicialmente identificou-se a família pela letra F com números subsequentes que identificam a ordem em que a coleta dos dados foi realizada, acrescido do nome fictício, mais o parentesco familiar.

A pesquisa atendeu os princípios éticos propostos pela Resolução no 196/96 (13), seguiu aos trâmites necessários para sua realização com seres humanos e foi registrada pelo Comitê de Ética da universidade em que o projeto estava vinculado, sob $n^{\circ}$ 0372.0.243.000-11. Além disso, está de acordo com os aspectos de rigor metodológico (adequação epistemológica, relevância, validez e reflexividade) propostos para pesquisas qualitativas (14).

\section{RESULTADOS}

Com relação às seis famílias pesquisadas, em quatro delas a pessoa que teve o IAM era do sexo masculino, com idade entre 54 e 65 anos, sendo a média 58,83 anos; o tempo de pós IAM ficou entre seis e onze meses; em todas as famílias participou pelo menos o casal, mas em três também outros familiares, como filhos (as) e nora; quanto a ocupação das pessoas que tiveram IAM, cinco eram aposentadas e uma era do lar. As ocupações dos demais membros das famílias variaram entre cozinheira, doméstica, costureira, estudante, do lar, babá, cuidadora de idosos, aposentado e policial.

O cuidado familiar foi organizado em duas categorias: Cuidado familiar como proteção e Cuidado familiar controlador.

\section{Cuidado familiar como proteção}

$\mathrm{Na}$ experiência das famílias o cuidado como proteção foi identificado nas ações que os integrantes desenvolviam para proporcionar assistência ao doente, determinando o bem- estar geral da família. Pode-se observar que as famílias criam estratégias de apoio, amparo e dedicação com o propósito de proteger os seus membros diante da enfermidade. Assim, evidenciou-se que o cuidado familiar como proteção era realizado por meio de situações que se caracterizam pela presença, pelo envolvimento, pela preocupação e pela busca de atividade econômica.

A presença pode ser percebida com as atividades desempenhadas no ambiente domiciliar, dentre elas cuidados com a alimentação, a medicação e a higiene:

Quando ela [nora] saia eu cuidava para ela, quando ela chegava, entregava para mim e aí eu levava para tomar banho, levava para fazer curativo, fazia tudo em casa. Comprei um aparelho para tirar a glicose da mão dele, tudo isso ai a gente fazia (F1-Cleusa-esposa).

$E$ aí foi indo com a recuperação, alimentação também cuidar um pouco. Até para tomar banho os primeiros dias sempre, para me vestir às vezes, para me abaixar não conseguia, doía aqui. Sempre com ajuda e foi indo, foi indo devagarinho (F5-Luis-doente). 
Em outros momentos, as famílias buscavam proteger se envolvendo no cuidado direto aos doentes, evitando, por exemplo, que estes desenvolvessem atividades que exigiam esforço físico:

É para ele se cuidar, não estar levantando muito peso, não estar forcejando. Às vezes eu digo para ele, dorme de tarde bastante, aproveita, fica dormindo, logo descansa (F1-Cleusa-esposa).

Ás vezes ele saia de carro, ia para o centro e eu dizia: se cuida, mas se cuida das coisas normais, não vai fazer um exercício. Se cuida no sentar, no levantar uma cadeira pesada, no descer escada (F5-Ana-esposa).

Outra situação descrita como forma de proteção foram as preocupações cotidianas da vida familiar. Em alguns casos, estas eram omitidas até que a recuperação do doente fosse retomada:

Quando ele saiu [do hospital], chegavam as contas altas e ele não podia saber de nada, tinha que ficar tranquilo, sem se incomodar, sem se preocupar com elas, aí a gente tinha que esconder e ficar tudo bem (F1-Daiane-nora).

Às vezes eu tinha dor, eu me segurava e chorava sozinha no quarto, eu me encerrava [...] para aquilo passar [...] (F1-Cleusa-esposa).

Ainda detectou-se que, principalmente nas entrevistas em que as pessoas que tiveram o IAM foram homens, as esposas necessitaram buscar uma atividade econômica que fornecesse subsídios financeiros ou então modificar as que já tinham, no intuito de proteção do núcleo familiar:

Ela [esposa] também mudou a vida dela, o trabalho dela mudou, teve que passar a trabalhar diferente (F5-Luis-doente).

Eu me virei, eu trabalhei, pode perguntar para ele, faz quatro anos que eu trabalho na creche. [...] tem as gurias [filhas] que trabalham [...] E ele ficava em casa porque essa guria aqui também já se vira (F2-Vera-esposa).

\section{Cuidado familiar controlador}

Nas famílias pode-se evidenciar também a presença de um cuidado controlador diante do adoecimento, uma vez que os familiares em diversas situações o conduzem sob uma perspectiva de vigilância e imposição, no cotidiano do sujeito doente. Esse cuidado familiar desenvolveu-se por meio de atitudes infantilizadoras e de controle, bem como por práticas autoritárias.

Após a internação hospitalar devido ao IAM, o doente retorna ao domicílio, emergindo algumas atitudes infantilizadoras da família frente aos cuidados realizados:

Ele dá um pouco de trabalho, virou criança. [...] uma coisa eu aprendi sabe, quando a gente começa a ficar na idade que a gente está, a gente envelhece e volta a [ser] criança. Eu [penso] mas será que eu estou criando filho de novo? (F1-Cleusa-esposa).

Tem que trazer a tua mãe assim, é nenezinho (F6-José-marido).

Por outro lado, percebeu-se que a condição de estar inferiorizado/infantilizado pode emanar, primeiramente, da própria pessoa que teve o IAM, conforme destacado:

Eu ficava mais assim os primeiros dias, não conseguia [...] Também sente a parte psicológica, muda muito [...] Agora estou adquirindo confiança [...] mas ficava pensando e claro isso entrava na minha cabeça, que eu tinha um problema (F5-Luis-paciente).

Outro aspecto destacado pelas famílias, quando mencionaram o enfermo, foi a sua resistência quanto aos cuidados necessários, fato que culmina nas atitudes de controle:

Ele sente dor ainda, ele não pode forcejar e dá aquela falta de ar desesperada. Domingo ele foi tentar limpar o pátio, sabe como ele é teimoso. E dai dava aquele suador e ele parava e doía. A gente fala as coisas pra ele não fazer, ele quer 
fazer e não pode (F1-Cleusa-esposa).

Tinha que estar cuidando, bem cuidado. Ela é meio teimosa também, sempre queria fazer uma coisa que não [podia], comer uma coisa que não devia (F4-Renato-companheiro/amigo).

$\mathrm{Na}$ busca de efetivar o cuidado, se percebem algumas tentativas de domínio da família frente às atitudes dos sujeitos que tiveram o IAM, por meio de práticas autoritárias:

Quando ele deu alta nós tentamos, eu tentei tirar [o cigarro]. Aí ele ficou assim, eu dava de hora em hora um pedacinho de cigarro, ele pegava e fumava um pedacinho. Foi indo, aí ele já se soltou mais, começou a sair, a comprar uma carteira e aí ele fumou, não era para fumar. Mas ele não deixa do cigarro (F2-Veraesposa).

\section{DISCUSSAÕ E CONCLUSÃO}

Em relação ao cuidado familiar como proteção, destaca-se que esse busca evitar novo IAM e desequilíbrio familiar, pois vários cuidados relatados pelas famílias desta pesquisa se referem aos momentos decorrentes do pós IAM imediato. Para a efetivação desses cuidados, a presença física parece ter uma significância considerável para os familiares, já que no momento em que estão próximos do enfermo conseguem acompanhar sua condição e prestar o suporte necessário.

A proteção familiar visa preservar a vida do doente, sendo, por isso, realizados cuidados com a higiene pessoal, adequação da habitação e alimentação, conforme as demandas do grupo. A família, como grupo, é corresponsável pela saúde e bem-estar dos seus membros (4) e em um processo de doença pode tornar-se aliada dos profissionais de saúde colaborando para a recuperação da saúde (15).
Para a pessoa que está debilitada e em sofrimento, sobretudo no pós IAM imediato, devido à dificuldade de realizar as atividades autonomamente, receber atenção e carinho por meio da presença possibilita a interação entre os envolvidos. Dessa forma, estudo (6) destaca que os fatores subjetivos podem atuar de maneira benéfica sobre a doença, estabelecendo terapêuticas que vão além dos medicamentos.

Embora os cuidados aparentemente pareçam ser voltados para a pessoa que está doente, muitos deles protegem a família em sua totalidade, pois facilitam o fortalecimento dos vínculos, estabelecem um ambiente saudável e podem diminuir o risco de novos problemas afetarem o núcleo familiar.

Lembrar o doente de suas fragilidades frente à doença pode fortalecer o cuidado, fazendo com que este seja compartilhado em ambiente familiar. Porém, não basta a família determinar opções estanques de cuidado ao enfermo, ela precisa realizar negociações internas, pautadas nas crenças e hábitos do grupo, que possam influenciar beneficamente no manejo da doença e na forma com que os membros se cuidam e se protegem.

Diante das limitações impostas pela doença, a família busca alternativas para gerenciar o cuidado, atendendo às demandas do doente dentro da sua perspectiva (16). A interação da família, quando positiva, pode favorecer o processo de enfrentamento da doença, colaborando para a execução de atitudes protetivas relacionadas à essência do que está sendo vivido (6).

Além disso, são percebidas, nas falas dos participantes do estudo, algumas inquietações, principalmente, no que se refere à necessidade iminente de evitar a disseminação de problemas do contexto familiar. Quando os familiares compreendiam as imposições do processo saúde/doença pareciam adentrar com mais facilidade na realidade, acentuando as forças de cuidado para sustentar as circunstâncias, como no caso das falas que demonstram a preservação do doente frente 
às adversidades que surgem.

O equilíbrio familiar, nesse período, tende a ser alcançado de maneira diferente, ocorrendo para isso uma introspecção familiar (12), na qual as práticas de cuidado são veladas ao contexto externo, e almejam resguardar a vida de quem teve o IAM.

Observou-se também que os integrantes das famílias se ajustavam às demandas, no intuito de proteção coletiva, mesmo que para isso fosse necessário sofrer silenciosamente, evitando gerar ansiedade no doente, bem como prejudicar seu funcionamento cardíaco novamente.

A preocupação da família representa uma ação de afeto que oferece qualidade ao cuidado (17) que pode auxiliar na recuperação. Nesses momentos pode existir também uma inversão de papéis e de responsabilidades, confirmando a doença como algo que interfere na vida de todos que estão próximos da pessoa que teve o IAM.

Salienta-se, portanto, que o comportamento padrão pré-determinado culturalmente pelo grupo familiar deixa de acontecer (12), incitando uma transformação não programada dos papéis na família. Desse modo, identificou-se nas famílias, um sentimento forte que as motivava para seguirem em frente e, passado algum tempo das adversidades do IAM, suas consequências crônicas foram, de certa forma, assimiladas, elaborando um novo padrão que deveria perdurar até que outra demanda familiar surgisse.

O IAM imediato, exige repouso, uma vez que a pessoa deve se recuperar do adoecimento evitando esforços. Portanto, torna-se coerente o afastamento, por vezes momentâneo e em algumas situações permanente, das atividades laborais. Devido a isso, se percebeu nas famílias entrevistadas uma dificuldade financeira, comprometendo a renda familiar.

No momento em que a doença envolve um dos membros da família, que auxilia financeiramente no ambiente familiar, evidenciam-se problemas relacionados à saída da pessoa do círculo de trabalho e também à diminuição da renda (8). Como forma de amenizar essa situação, detectou-se, nos achados desta pesquisa, que as mulheres que tinham a função de complementar as finanças, necessitaram trabalhar ou modificar seus hábitos laborais a fim de manter o padrão de vida e proteger a família na sua unicidade. A mulher então permanece mais tempo fora de casa e inverte seu papel de provedora de cuidados para o lar, para provedora de sustento.

Em relação ao cuidado familiar controlador, apesar do IAM se caracterizar como um acontecimento agudo que necessita de internação hospitalar, seus reflexos continuam no domićlio, influenciando no modo de agir e viver dos integrantes da família. Assim, diante das modificações necessárias para se retomar o equilíbrio, a família passa a elaborar restrições superprotetoras, colocando o sujeito doente, muitas vezes, em condição de incapacidade, como se fosse uma criança que precisa de cuidados e não tem autonomia para fazê-los.

Esse cuidado exacerbado ocasiona, de certa forma, a descaracterização da pessoa como um ser adulto e pode surgir a partir da busca dos familiares em atender todas as necessidades para sobrevivência do doente (18). Isso pode ser detectado, já que as famílias devido ao medo das consequências passaram a ter um cuidado maior com seus entes queridos e assim desenvolveram práticas de infantilização. Salienta-se que essa situação pode persistir, mesmo quando o doente apresenta sinais de recuperação e possibilidade de desenvolver as atividades de forma autônoma.

A família deve atentar para a autonomia de quem teve o IAM, pois, senão, à medida que se estabelece uma dependência, como a identificada nas falas, pode-se também favorecer um comportamento infantil nas pessoas doentes (18). Há necessidade de equilíbrio familiar até mesmo nas práticas de cuidado dos integrantes, o que pode ser comparado com uma balança que necessita estar com ambos os lados em sintonia para que nenhum exerça força demais sobre o ou- 
tro. Retratando o contexto familiar, o doente e o restante da família devem ponderar suas ações, mantendo um balanceamento que seja adequado para todos os envolvidos e que evite a hierarquização de papéis.

Pode ser ainda que o doente demonstre fragilidades e receios para a retomada de seus hábitos, sugerindo até mesmo alterações psicológicas, ocasionadas por sua condição. Dessa forma, o mesmo pode se colocar em uma posição inferior e, estimular a família a vê-lo também da mesma forma, suscitando modificações nos papéis.

As relações existentes na família não são estáveis e, quando se modificam, são precedidas por alterações na realidade, como o surgimento de uma doença (12). Assim, por meio desses arranjos que ocorrem entre os membros da família após o IAM, os doentes modificam seu papel dentro do grupo (12) e podem desenvolver problemas relacionados à autoestima devido à inferiorização sentida pela perda de posição na família (9).

Com vistas a propiciar a autonomia do doente em âmbito familiar, a Enfermagem pode colaborar, inserindo a família desde a internação hospitalar nas práticas de cuidado, demonstrando ao grupo as ações a serem realizadas no domicílio em cada etapa da recuperação pós IAM. Com o conhecimento das possibilidades do enfermo, a família pode sentir-se mais segura e facilitar que ele exerça sua autonomia.

Em determinadas falas das famílias entrevistadas o controle parece estar imbricado através da utilização das expressões "não pode" e "não deve", as quais sugestionam certa autoridade perante as fragilidades que a doença impõe. No entanto, neste estudo, as pessoas que tiveram infarto tentavam agir de acordo com suas atividades rotineiras, no intuito de sentirem-se úteis, já que, na sua maioria, não ficaram com sequelas físicas graves.

Ainda, verificou-se que ocorre uma tentativa de influência da família sobre os com- portamentos do doente (12) e à medida que as necessidades de saúde começam a ser parcialmente resolvidas, havendo recuperação do corpo físico, os doentes se sentem aptos para retornar às suas atividades de vida diária (8) e, mesmo que nem sempre se sintam bem, fazem tentativas para demonstrar ao restante da família que podem exercer sua autonomia. Apesar disso, essas atitudes de retomada de vida normal, por vezes, podem prejudicar ainda mais a saúde, mas revelam a busca dos doentes pela liberdade de domínio da família e, também da doença sobre todos, pois à medida que o enfermo passa a exercer suas atividades, o IAM deixa de ser tão focalizado no contexto familiar e as preocupações desviam para outras questões que não a doença.

A rotina familiar tende a ser retomada como estratégia de enfrentamento da família, evitando maior desequilíbrio aos outros integrantes que também precisam de cuidados no decorrer de sua existência (19). Por meio das práticas de educação em saúde, que permitem uma troca entre os conhecimentos popular e profissional, a Enfermagem pode alertar a família quanto às limitações e especificidades do IAM. Assim, com certa compreensão do processo saúde/doença, poderão ser amenizadas angústias de todos envolvidos e, por conseguinte, pressões de domínio da família sobre o doente e suas atividades cotidianas. O desenvolvimento da educação familiar pode ainda oferecer suporte, reduzindo os problemas no domicílio e a demanda nos serviços de saúde (20).

As práticas autoritárias realizadas por alguns integrantes da família parecem ser uma tentativa de mudança de hábitos e crenças, o que se torna difícil devido as singularidades e experiências de cada pessoa. Compreende-se que algumas dessas situações fazem parte de um movimento do grupo para fortalecer o cuidado familiar e evitar novo problema, porém sem considerar, de certo modo, a rotina que o doente tinha antes do IAM. Então, se 
percebe que não são somente os profissionais de saúde, como muitas vezes são criticados, têm dificuldade para vislumbrar as características de cada indivíduo. A própria família, que convive cotidianamente com o doente ultrapassa os hábitos que até então eram do âmbito familiar.

É necessário lembrar que os hábitos são influenciados pelo contexto em que as pessoas vivem (21) e, assim, a própria família, anteriormente ao episódio de IAM, pode ter colaborado para o desenvolvimento dos costumes que o doente opta por seguir, como o uso do cigarro apresentado no depoimento. Ainda, o processo de mudança após a doença não ocorre igualmente em todos os membros da família, ou seja, alguns são menos capazes de sofrer as influências da enfermidade (12), sendo que esta também pode ser uma justificativa para os que retomam hábitos anteriores.

Esses dados confirmam a necessidade da Enfermagem atuar junto com a família, auxiliando no esclarecimento do processo saúde/ doença e fornecendo subsídios que possam reduzir os conflitos emergentes. Ao se realizar um diagnóstico familiar, novas possibilidades para a resolução de problemas podem ser sugeridas, o que facilita a interação e boa convivência entre todos, sem a necessidade de práticas impositivas e críticas à pessoa que teve o IAM.

Por meio da realização deste estudo pôde-se perceber que o cuidado familiar desenvolvido após IAM, nas famílias entrevistadas, apresenta, principalmente, características protetivas e de controle. Ao se referirem aos cuidados de proteção, destacam-se aqueles relacionados à alimentação, à higiene, à medicação e também ao esforço físico e às preocupações que devem ser evitadas. Alguns são realizados pelas famílias em período imediato após o IAM, porém outros até podem perpetuar como uma modificação no cotidiano do grupo, exigindo adaptações.

Por outro lado, detectaram-se cuidados de controle da família para com a pessoa que teve o IAM, como atitudes infantilizadoras e críticas à sua resistência, o que culmina na tentativa de domínio da família, com posturas autoritárias e atitudes que desconsideram, por vezes, sua própria cultura, e que podem interferir na autonomia do enfermo frente à sua conduta de vida. Isso talvez ocorra pela modificação do papel do enfermo dentro do contexto familiar.

Em uma primeira análise dos cuidados destacados neste artigo, eles parecem ser opostos, porém questiona-se: até que ponto? Em alguns contextos até podem ser, mas nos ambientes familiares desta pesquisa percebeu-se que, ao mesmo tempo ou alternadamente, o cuidado que controla, protege, e vice-versa, sendo, portanto, modos diferentes de alcançar um mesmo objetivo que é atenuar os efeitos da doença sobre a família. Isso confirma que a família não é estática, sobretudo, pelas interações que ocorrem em seu interior e que permitem esse contraponto de cuidados. Destaca-se também que esses cuidados facilitam por vezes as aproximações ou conflitos entre os integrantes.

Os achados deste estudo possibilitaram conhecer o cuidado que as famílias elaboram e desenvolvem frente ao IAM, sendo possível até mesmo dizer que no interior da familia existem diversas formas de desenvolver o cuidado, sendo este, portanto, multifacetado. Acredita-se que por meio desses resultados se estará favorecendo para Enfermagem e as outras profissões da área da saúde, uma visualização mais aprofundada do cuidado familiar e suas variações. Desse modo, pode-se buscar sua inserção nos serviços de saúde, facilitando uma proximidade entre cuidado familiar e profissional. Ainda, com esta pesquisa percebeu-se que são necessários novos estudos, os quais consigam aprofundar os cuidados realizados, atentando para as significações deles nas famílias, bem como as interações que os permeiam em cada momento de enfrentamento da doença. 


\section{REFERÊNCIAS}

1. Mansur AP, Favarato D. Mortalidade por doenças cardiovasculares no Brasil e na região metropolitana de São Paulo: atualização 2011. Arq Bras Cardiol. 2012; 99(2): 755-61.

2. Figueiredo AE, Siebel AL, Luce DC, Schneider I. Determinação do tempo de apresentação a emergência de pacientes com infarto agudo do miocárdio. Rev Enferm UFSM. 2013; 3(1): 93-101.

3. Leininger M, McFarland MR. Culture care diversity and universality: a world wide nursing theory. $2^{\text {nd }}$ ed. Sudbury, MA: Jones and Bartlett; 2006. p. 43-82.

4. Elsen I. Cuidado familial: uma proposta inicial de sistematização conceitual. En: Elsen I, Marcon SS, Silva MRS, organizador. $\mathrm{O}$ viver em família e sua interface com a saúde e a doença. $2^{\text {a }}$ ed. Maringá: Eduem; 2004. p. 19-28.

5. Oliveira APL, Sarmento SS, Mistura C, Jacobi CS, Girardon-Perlini NMO, Carvalho e Lira MOS, et al. Experiência de familiares no cuidado a adolescentes com diabetes mellitus tipo 1. Rev Enferm UFSM. 2013; 3(1): 133-43.

6. Budó MLD, Resta DG, Denardin JM, Ressel LB, Borges ZN. Práticas de cuidado em relação à dor - A cultura e as alternativas populares. Esc Anna Nery. 2008; 12(1): 90-6.

7. Sousa SM, Bernardino E, Vicelli RMM, Kalinowski CE. Perfil de pacientes submetidos ao cateterismo cardíaco: subsídio para prevenção de fatores de risco cardiovascular. Cogitare Enferm. 2014; 19(2): 304-8.

8. Caetano JA, Soares E. Qualidade de vida de clientes pós-infarto agudo do miocárdio. Esc Anna Nery. 2007; 11(1): 30-7.

9. Galter C, Rodrigues GC, Galvão ECF. A percepção do paciente cardiopata para vida ativa após recuperação de cirurgia cardiaca. J Health Sci Inst [Internet].
2010 [citado em 28 nov 2012]; 28(3): 255-8. Disponível em: http://www.unip. br/comunicacao/publicacoes/ics/edicoes/2010/03_jul-set/V28_n3_2010_p255258.pdf

10. Camacho TP, Barboza MCN, Roese A. Trajetórias percorridas por usuários com doença cardiovascular até a internação hospitalar. Rev Enferm UFSM [Internet]. 2013 Set-Dez [citado em 12 dez 2013]; 3(3): 509-17. Disponível em: http://cascavel.ufsm.br/revistas/ojs-2.2.2/index. php/reufsm/article/view/8233/pdf

11. Minayo MCS. O desafio do conhecimento: pesquisa qualitativa em saúde. $14^{\mathrm{a}} \mathrm{ed}$. São Paulo: Hucitec; 2014.

12. Wright LM, Leahey M. Enfermeiras e famílias: um guia pra avaliação e intervenção na família [trad. Sílvia Spada]. 5ª ed. São Paulo: Roca; 2012. 350 p.

13. Brasil. Conselho Nacional de Saúde. Resolução 196/96 - Pesquisa em Seres Humanos, Brasília: Ministério da Saúde; 1996.

14. Calderón C. Criterios de calidad en la investigación cualitativa en salud (ICS): apuntes para un debate necessário. Rev esp salud publica. 2002; 76(5): 473-82.

15. Koerich C, Baggio MA, Erdmann AL, Lanzoni GMM, Higashi GDC. Revascularização miocárdica: estratégias para o enfrentamento da doença e do processo cirúrgico. Acta paul enferm. 2013; 26(1): 8-13.

16. Donovan R, Williams A, Stajduhar K, Brazil K, Marshall D. The influence of culture on home-based family caregiving at end-of-life: A case study of Dutch reformed family care givers in Ontario, Canada. Soc Sci Med. 2011; 72(3): 33846.

17. Brondani CM, Beuter M, Alvim NAT, Szareski LSR. Cuidadores e estratégias no cuidado ao doente na internação domiciliar. Texto contexto-enferm. 2010; 19(3): 504-10.

18. Floriano LA, Azevedo RCS, Reiners AAO, 
Sudré MRS. Cuidado realizado pelo cuidador familiar ao idoso dependente, em domicílio, no contexto da estratégia de saúde da família. Texto contexto-enferm. 2012; 21(3): 543-8.

19. Quirino DD, Collet N. Câncer no lactente: readaptações na vida familiar. Texto Contexto Enferm. 2012; 21(2): 295-303.

20. Chien WT, Lee IY. Randomized controlled trial of a dementia care programme for families of home-resided older people with dementia. J Adv Nurs. 2011; 7(4): 774-87.

21. Cruz SEE, Osorio FR. Percepciones y creencias en personas que padeciero nun evento coronario agudo. Av. enferm. 2011; XXIX(2): 307-18. 